\title{
Temporary Right Middle Lobe Occlusion with a Blocking Device to Enable Collateral Ventilation Measurement of the Right Major Fissure
}

\author{
Jorrit B.A. Welling ${ }^{a, b}$ T. David Koster ${ }^{a, b}$ Jorine E. Hartman ${ }^{a, b}$ \\ Marlies van Dijk ${ }^{a, b}$ Huib A.M. Kerstjens ${ }^{a, b}$ Karin Klooster $^{a, b}$ Dirk-Jan Slebos ${ }^{a, b}$ \\ a Department of Pulmonary Diseases, University Medical Center Groningen, University of Groningen, Groningen, \\ The Netherlands; ${ }^{b}$ Groningen Research Institute for Asthma and COPD, University Medical Center Groningen, \\ University of Groningen, Groningen, The Netherlands
}

\section{Established Facts}

- Chartis measurement of the lower lobes can be hampered by a "no-flow" phenomenon, preventing a reliable measurement of interlobar collateral ventilation.

- In the left lung, this can easily be resolved by performing measurement of the left major fissure in the left upper lobe.

- Measurement of the right major fissure in the right upper lobe is not directly possible because of the presence of the right middle lobe.

\section{Novel Insights}

- Temporary occlusion of the right middle lobe will facilitate a reliable Chartis measurement of the right major fissure in the right upper lobe.

- This occlusion can easily be performed using either a Watanabe spigot or a balloon catheter.

\section{Keywords}

Chartis measurement $\cdot$ No-flow phenomenon $\cdot$ Right middle lobe occlusion

\section{Abstract \\ Background: Absence of interlobar collateral ventilation is essential to achieve lobar volume reduction after endobron- chial valve (EBV) treatment and can be assessed using the Chartis measurement. However, especially in lower lobe measurements, Chartis can be complicated by the "no-flow}

phenomenon", during which a sudden cessation of flow is observed, leading to an unreliable measurement. If this phenomenon occurs in the right lower lobe, when measuring collateral flow over the right major fissure, the entrance to the right middle lobe should be occluded, and the Chartis balloon should be placed in the right upper lobe. Both Watanabe spigots and balloon catheters can be used to achieve occlusion. Objective: Our aim was to demonstrate that right middle lobe occlusion with a blocking device is helpful in obtaining a reliable Chartis outcome in case of the no-flow phenomenon in the right lower lobe. Methods: We per-

$\begin{array}{ll}\text { karger@karger.com } & \text { (c) 2020 The Author(s) } \\ \text { Published by S. Karger AG, Basel } & \text { Karger } \\ \text { This article is licensed under the Creative Commons Attribution- } & \text { NonCommercial-NoDerivatives 4.0 International License (CC BY- } \\ \text { NC-ND) (http://www.karger.com/Services/OpenAccessLicense). } \\ \text { Usage and distribution for commercial purposes as well as any dis- } \\ \text { tribution of modified material requires written permission. }\end{array}$

Jorrit B.A. Welling, MD

Department of Pulmonary Diseases AA11

University Medical Center Groningen, PO Box 30001

NL-9700RB Groningen (The Netherlands)

j.b.a.welling@umcg.nl 
formed a retrospective analysis of patients scheduled for EBV treatment in an EBV registry between September 2016 and September 2019. Results: We included 15 patients with severe emphysema (median age 63 years [range 47-73], $73 \%$ female, and $\mathrm{FEV}_{1} 24 \%$ [range 19-36] of predicted), who required temporary middle lobe occlusion (12 Watanabe spigot, 3 balloon catheter). After occlusion, a reliable Chartis outcome was obtained in all patients. Conclusion: Temporary middle lobe occlusion using a blocking device is helpful in obtaining a reliable Chartis outcome in case of a right lower lobe no-flow phenomenon.

C) 2020 The Author(s)

Published by S. Karger AG, Basel

\section{Introduction}

The absence of interlobar collateral ventilation is essential to achieve lobar volume reduction with endobronchial valve (EBV) treatment in patients with severe emphysema and can be assessed using the Chartis ${ }^{\circledR}$ (Pulmonx, USA) measurement [1-4]. Chartis measurement can be complicated by the "no-flow phenomenon", in which dynamic expiratory airway collapse is believed to cause a sudden cessation of flow during measurement, leading to an unreliable Chartis measurement [5]. Literature shows that this can occur in up to one-third of all measurements and most frequently affects the lower lobes [5-7]. Normally, Chartis measurement is performed in the lobe selected for treatment with EBV. When the noflow phenomenon occurs during measurement in the left lung, measurement in the adjacent lobe can easily be performed to assess the integrity of the left major fissure [8]. However, in case of no flow in the right lower lobe, measurement of the right upper lobe may not be reliable because collateral flow originating from the right middle lobe, due to common incompleteness of the right minor fissure, can result in false-positive Chartis outcomes [1]. If the middle lobe is not occluded, the measurement in the right upper lobe only measures the collateral flow over the right upper lobe fissure (part of the major fissure and minor fissure) and not the right major fissure.

\section{Case Report}

\section{Methods}

We performed a retrospective analysis in which we included all patients with the right lower lobe as primary EBV target and in which the no-flow phenomenon occurred during Chartis measurement in the right lower lobe.

All patients were scheduled for treatment in the Dutch national EBV treatment registry (BREATH-NL) between September 2016 and September 2019 (Clinicaltrials.gov identifier: NCT02815683). Chartis measurements were performed in all patients regardless of fissure integrity scores. The presence of collateral ventilation was confirmed when a continuous, non-decreasing, expiratory airway flow was observed during $>6$ min or earlier with a similar pattern when totaling $>1 \mathrm{~L}$ [8]. Every patient underwent Chartis measurement under general anesthesia using a previously described approach [9]. Target lobe volume and fissure integrity were assessed using the StratX quantitative CT Platform (Pulmonx).

To achieve the desired temporary occlusion of the right middle lobe, both Watanabe spigots ${ }^{\circledR}$ (Novatech, France) and Extractor ${ }^{\circledR}$ Pro retrieval balloon catheters (Boston Scientific, USA), were used. The Watanabe spigot (Fig. 1) is a silicon bronchial filler, which is frequently used for persistent pneumothorax, hemoptysis, and bronchopleural fistula, and is available in three sizes: 5, 6 and $7 \mathrm{~mm}$ in diameter [10]. The retrieval balloon (Fig. 2) can be inflated to any desired diameter between 5 and $20 \mathrm{~mm}$ and can be replaced by any locally available alternative balloon.

Our primary outcome was the success rate of right upper lobe Chartis measurement of the right major fissure after occlusion of the right middle lobe and placement of the Chartis balloon in the right upper lobe. Our secondary outcome was the amount of target lobe volume reduction after EBV treatment.
Fig. 1. a Watanabe spigot. b Watanabe spigot held by a biopsy forceps, which can be used for both placement and removal of the spigot.
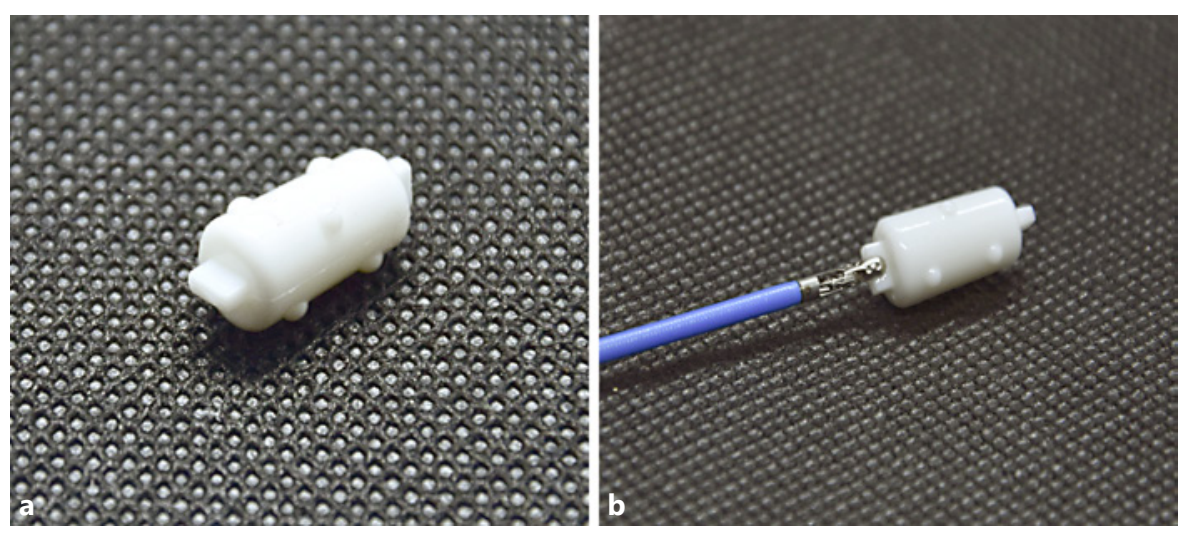

Chartis Assessment of the Right Major Fissure with Occlusion of the Right Middle Lobe
Respiration 2020;99:516-520 DOI: $10.1159 / 000507401$ 
Fig. 2. a Watanabe spigot occluding the entrance of the right middle lobe. b Balloon catheter occluding the entrance of the right middle lobe.
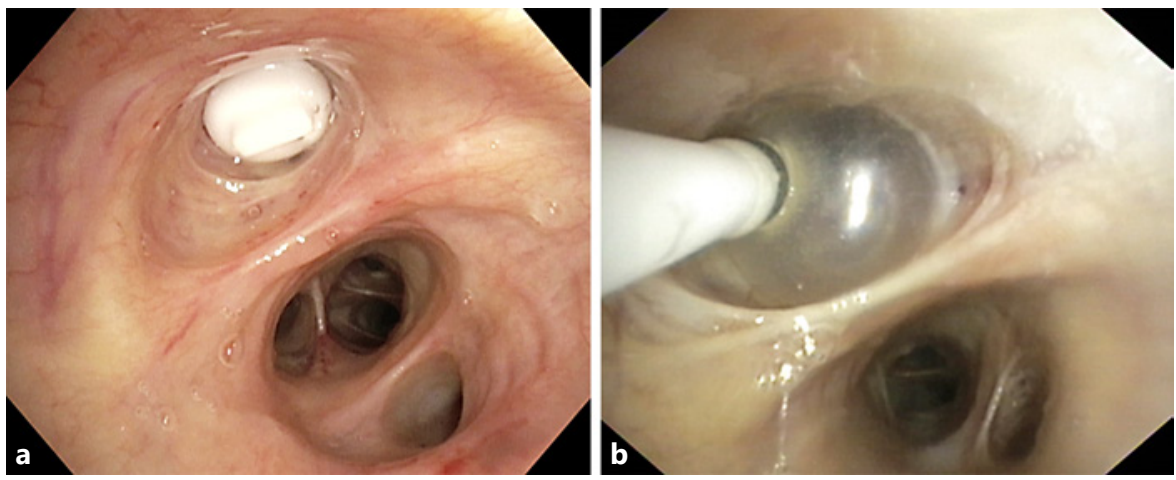

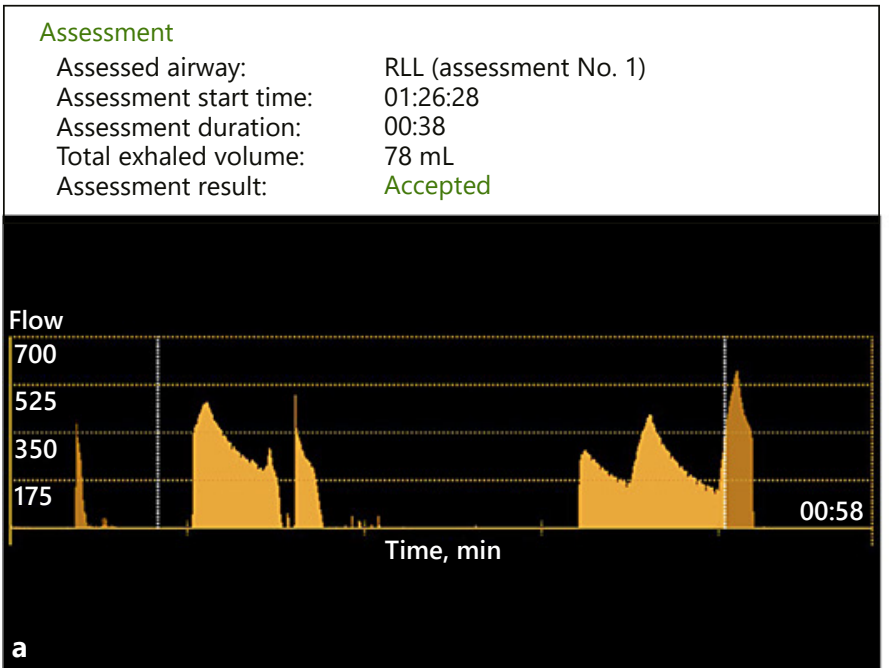

Fig. 3. a Chartis measurement output indicating the no-flow phenomenon in the right lower lobe. The initially present flow becomes zero after the balloon seal is achieved, flow returns when the catheter is withdrawn with subsequent loss of the balloon seal, rul-

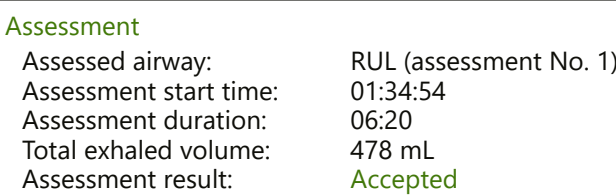

Assessed airway:

Assessment start time:

Assessment duration:

Total exhaled volume:

Assessment result:

RUL (assessment No. 1)

01:34:54

06:20

$478 \mathrm{~mL}$

Accepted

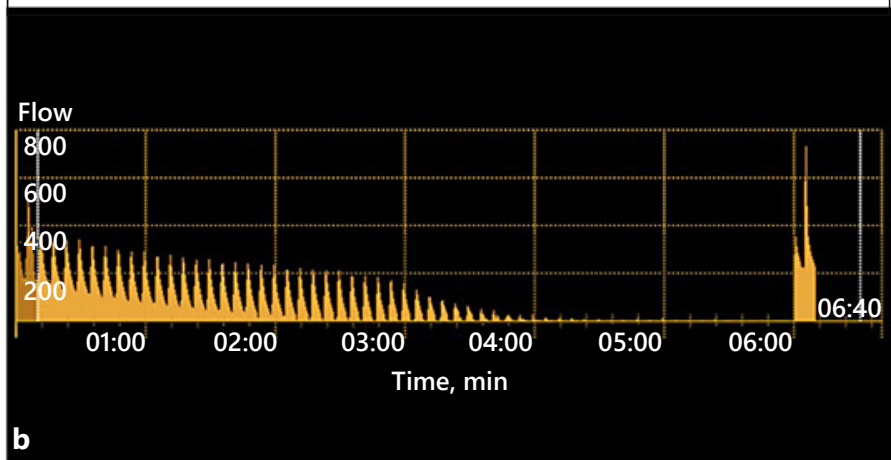

ing out other potential causes of no flow. $\mathbf{b}$ Chartis measurement output of the right upper lobe in the same patient, indicating absence of interlobar collateral ventilation after occlusion of the right middle lobe with a Watanabe spigot.
Table 1. Patient characteristics

\begin{tabular}{lc}
\hline Patients, $n$ & 15 \\
Female/male, \% & $73 / 27$ \\
Age, years & $63(47-73)$ \\
BMI & $22(19-30)$ \\
Pack years & $43(10-85)$ \\
FEV 1 predicted, \% & $24(19-36)$ \\
RVpredicted, \% & $229(187-317)$ \\
RV/TLC, ratio & $0.65(0.58-0.76)$ \\
6MWD, m & $320(15-484)$
\end{tabular}

Data are presented as median (range), unless otherwise indicated. BMI, body mass index; $\mathrm{FEV}_{1}$, forced expiratory volume in $1 \mathrm{~s}$; RV, residual volume; TLC, total lung capacity; 6MWD, 6-min walking distance.
Case Report

A 63-year-old female with severe emphysema (forced expiratory volume in $1 \mathrm{~s}\left[\mathrm{FEV}_{1]} 25 \%\right.$ of predicted and residual volume [RV] $214 \%$ of predicted) was scheduled for EBV treatment in our hospital. The predetermined target for treatment was the right lower lobe (51\% of voxels $<-950$ Hounsfield Units). We were initially unable to obtain a reliable Chartis measurement in the right lower lobe, as we encountered the no-flow phenomenon (Fig. 3a). After the occlusion of the right middle lobe with a Watanabe spigot, we performed a Chartis measurement in the right upper lobe, which indicated absence of interlobar collateral ventilation of the right major fissure (Fig. 3b). Subsequently, five endobronchial valves were placed in the right lower lobe. Six weeks after treatment, the patient achieved a target lobe volume reduction of $1,201 \mathrm{~mL}$, had an $\mathrm{FEV}_{1}$ of $40 \%$ of predicted ( $69 \%$ relative increase), and an RV of $148 \%$ of predicted $(31 \%$ relative reduction). 
In conclusion, selective temporary occlusion of the right middle lobe using a blocking device is helpful in obtaining a reliable Chartis outcome in case of the no-flow phenomenon in the right lower lobe. The application of this simple technique may improve patient selection and outcomes for EBV treatment.

\section{Acknowledgements}

We would like to thank Diemer Feenstra for his assistance with creating Figure 1.

\section{Statement of Ethics}

According to the ethics committee of our hospital, this study did not fall within the scope of the WMO (Dutch Medical Research with Human Subjects Law), and therefore formal ethical approval was not needed. All patients provided written informed consent.

\section{Disclosure Statement}

D.-J.S. is an investigator of and advisor to Pulmonx Inc., Redwood City, CA, USA. All other authors have no conflicts of interest to declare.

\section{Funding Sources}

University of Groningen, Junior Scientific Masterclass provided financial support for the research position of J.B.A.W.

\section{Author Contributions}

J.B.A.W. and D.-J.S. undertook conception and design of the study. T.D.K., M.v.D., K.K., and D.-J.S. performed the Chartis measurements and treatments. J.B.A.W., J.E.H., H.A.M.K., and D.-J.S. performed analysis and interpretation. All authors have read, improved, and approved the final version of the manuscript.

\section{References}

1 Koster TD, Slebos DJ. The fissure: interlobar collateral ventilation and implications for endoscopic therapy in emphysema. Int J Chron Obstruct Pulmon Dis. 2016 Apr;11:765-73.

2 Klooster K, ten Hacken NH, Hartman JE, Kerstjens HA, van Rikxoort EM, Slebos DJ. Endobronchial Valves for Emphysema without Interlobar Collateral Ventilation. N Engl J Med. 2015 Dec;373(24):2325-35.

3 Criner GJ, Sue R, Wright S, Dransfield M, Rivas-Perez H, Wiese T, et al.; LIBERATE Study Group. A Multicenter Randomized Controlled Trial of Zephyr Endobronchial Valve Treatment in Heterogeneous Emphysema (LIBERATE). Am J Respir Crit Care Med. 2018 Nov;198(9):1151-64.

4 Herth FJ, Eberhardt R, Gompelmann D, Ficker JH, Wagner M, Ek L, et al. Radiological and clinical outcomes of using Chartis ${ }^{\mathrm{TM}}$ to plan endobronchial valve treatment. Eur Respir J. 2013 Feb;41(2):302-8.
5 Gesierich W, Samitas K, Reichenberger F, Behr J. Collapse phenomenon during Chartis collateral ventilation assessment. Eur Respir J. 2016 Jun;47(6):1657-67.

6 Gesierich W, Samitas K, Behr J. Determining collateral ventilation during bronchoscopy: unanswered questions. Thorax. 2014 Mar; 69(3):289-90.

7 Herzog D, Thomsen C, Poellinger A, Doellinger F, Schreiter N, Froeling V, et al. Outcomes of Endobronchial Valve Treatment Based on the Precise Criteria of an Endobronchial Catheter for Detection of Collateral Ventilation under Spontaneous Breathing. Respiration. 2016;91(1):69-78.

8 Slebos DJ, Shah PL, Herth FJ, Valipour A. Endobronchial Valves for Endoscopic Lung Volume Reduction: Best Practice Recommendations from Expert Panel on Endoscopic Lung Volume Reduction. Respiration. 2017;93(2): 138-50.
9 Welling JB, Klooster K, Hartman JE, Kerstjens HA, Franz I, Struys MM, et al. Collateral Ventilation Measurement Using Chartis: Procedural Sedation vs General Anesthesia. Chest. 2019 Nov;156(5):98490.

10 Watanabe Y, Matsuo K, Tamaoki A, Komoto R, Hiraki S. Bronchial Occlusion With Endobronchial Watanabe Spigot. J Bronchology Interv Pulmonol. 2003;10:264-7.

11 Welling JB, Hartman JE, van Rikxoort EM, Ten Hacken NH, Kerstjens HA, Klooster K, et al. Minimal important difference of target lobar volume reduction after endobronchial valve treatment for emphysema. Respirology. 2018 Mar;23(3):306-10. 